\title{
Article \\ Development of a Caterpillar-Type Walker for the Elderly People
}

\author{
Yeon-Kyun Lee ${ }^{1}$, Chang-Min Yang ${ }^{1}$, Sol Kim ${ }^{1}$, Ji-Yong Jung ${ }^{2} \mathbb{C}$ and Jung-Ja Kim ${ }^{2,3, *}$ \\ 1 Department of Healthcare Engineering, Jeonbuk National University, 567 Baekje-daero, Deokjin-gu, \\ Jeonju-si 54896, Korea; yglee0406@gmail.com (Y.-K.L.); didckdals10@gmail.com (C.-M.Y.); \\ demers705@gmail.com (S.K.) \\ 2 Division of Biomedical Engineering, Jeonbuk National University, 567 Baekje-daero, Deokjin-gu, \\ Jeonju-si 54896, Korea; cholbun84@jbnu.ac.kr \\ 3 Research Center of Healthcare \& Welfare Instrument for the Aged, Jeonbuk National University, \\ 567 Baekje-daero, Deokjin-gu, Jeonju-si 54896, Korea \\ * Correspondence: jungjakim@jbnu.ac.kr; Tel.: +82-63-270-4102
}

Citation: Lee, Y.-K.; Yang, C.-M.; Kim, S.; Jung, J.-Y.; Kim, J.-J. Development of a Caterpillar-Type Walker for the Elderly People. Appl. Sci. 2022, 12, 383. https://doi.org/10.3390/app 12010383

Academic Editor: Redha Taiar

Received: 24 November 2021

Accepted: 28 December 2021

Published: 31 December 2021

Publisher's Note: MDPI stays neutral with regard to jurisdictional claims in published maps and institutional affiliations.

Copyright: (c) 2021 by the authors Licensee MDPI, Basel, Switzerland. This article is an open access article distributed under the terms and conditions of the Creative Commons Attribution (CC BY) license (https:// creativecommons.org/licenses/by/ $4.0 /)$.

\begin{abstract}
A walker assists elderly people with age-related reduced walking ability and helps to improve stability and balance ability. However, if the general-type walker (GTW) is used on an uneven, obstacle, or sloped terrain, it may cause excessive muscle use and falls. Therefore, in this study, we developed a caterpillar-type walker (CTW) that elderly people can safely use in various terrains. Twelve elderly who were able to walk normally participated in the study. The activity of upper and lower extremity muscles, the number of obstacles overcome, and walking speed was compared and analyzed when using two types of walkers in uneven terrain, obstacle terrain, and sloped terrain. In addition, satisfaction with the use of these walkers was evaluated. When CTW was used, the activity of the muscles of the upper and lower extremities was significantly reduced compared to the use of GTW on all terrains. The walker developed in this study overcame obstacles of all heights, but the GTW failed to overcome obstacles starting from the $2 \mathrm{~cm}$ section. In terms of walking speed, when the CTW was used, the walking speed was higher than that of the GTW in uneven terrain and obstacle terrain. In satisfaction, there were significant differences in safety, durability, simplicity of use, comfort, and effectiveness. Through these results, it was confirmed that the CTW can efficiently and safely assist the elderly in walking on uneven terrain, obstacle terrain, and inclined terrain.
\end{abstract}

Keywords: walker; caterpillar; elderly; various terrain; muscle activity

\section{Introduction}

The proportion of the global population aged 65 and over is increasing. Korea is an aging society, with the elderly exceeding $14 \%$ of the total population as of 2017 . Currently, the proportion of the elderly population makes up $15.7 \%$ of the population, and it is expected that Korea will be entering a super-aging society by 2025 [1,2]. Aging and its associated deterioration in physical function are directly related to changes in exercise capacity. As aging progresses, sensory functions and reflexes deteriorate, and overall muscle strength decreases. In the case of lower extremity muscle strength, it decreases by $40 \%$ compared to adults in their $30 \mathrm{~s}$, causing problems with body balance function, which results in decreased walking ability [3]. This decline in gait function becomes noticeable after the age of 75-80. The gait pattern of these elderly tends to a slouched posture, a shorter gait distance, and a wide distance between the feet, which is called essential senile gait disorder [4,5]. This decline in the walking ability not only causes many restrictions on the daily life of the elderly but also becomes a major cause of falls. Falls account for the second-highest percentage of elderly deaths and occur at the highest frequency among elderly injury factors. This phenomenon is recognized as a serious problem for many countries [6]. According to a 2017 survey concerning the condition of the elderly, 15.9\% 
of all elderly had a fall accident in the past year [7]. Among the major causes of these falls, walking environment $(31 \%)$, as well as gait and balance disorders $(17 \%)$, was the biggest contributor. Moreover, the decline in mobility interfered with social life, leading to depression and possibly other adverse mental health outcomes $[8,9]$.

A walker is often used by the elderly to maintain a social life and physical activity. As they are light and inexpensive, most elderly use them throughout their daily activities. The walking assistance market for the elderly is expected to continue to grow [10-14]. The general circular wheel, which has been widely used in most walkers, is difficult to operate on external walking paths with rough or uneven surfaces. When crossing obstacles, the impact applied to the walker is transmitted to the user directly, and the user can fall if it collides with an obstacle. In addition, when using the walker on a downhill slope, the elderly with a reduced upper extremity muscle strength can lose the walker. On the other hand, on an uphill slope, considerable weight is applied to the rear handle making the center of gravity unaligned, which can cause the front side of the walker to lift, inducing a fall [15-18].

To compensate for these shortcomings, a previous study has developed an algorithm that analyzes the amount of vibration when crossing obstacles for attenuating shock and diminishing the vibration generated on the handlebar [19]. In another previous study, a walker that can be used comfortably and safely was developed by reducing the vibration transmitted to the user based on the analysis of the mass ratio, damping ratio, and natural frequency occurring in various road environments [20]. Choi et al. proposed an algorithm that can control a motor-based electric walker for safe walking by calculating the speed and the inclination of the ground from the center of pressure of the foot, using a force-sensing resistor (FSR) [21]. Additionally, based on the EMG experiment, a walker equipped with an active brake that could be used for various purposes was developed to assist the elderly in rural environments where roads are rough and bumpy [22]. However, there has been a lack of research on a device that can solve the problems associated with slipping on slopes, excessive use of muscles to overcome obstacles and wheel obstruction in uneven terrain.

Since the caterpillar moves by traction force due to friction acting on a large contact area with the ground, it is suitable for use on uneven or sloped ground [23]. Therefore, a walker equipped with a caterpillar wheel and motor was developed to solve the problems of the wheel obstruction on uneven terrain, excessive use of muscles on obstacle terrain, and rolling phenomenon on sloped terrain. Actually, elderly people use a walker on walking paths with uneven terrain, obstacle terrain, and sloped terrain. Therefore, we constructed three types of terrains (uneven terrain with gravel, obstacle terrain with obstacles of different heights, and sloped terrain with uphill or downhill slopes) to test the efficiency of the designed walker. Then, the activity of the upper and lower extremity muscles, the number of obstacles overcome, and the walking speed measured when using a generaltype walker and a caterpillar-type walker were comparatively analyzed. In addition, the difference in usability between the existing walker and the developed walker was evaluated by comparing the satisfaction according to a questionnaire survey.

\section{Materials and Methods}

\subsection{Design of Caterpillar-Type Walker}

Currently, most walkers are used outdoors, including uneven terrain, obstacle terrain, and sloped terrain, to provide stable walking assistance and prevent falls in the elderly. In this study, a walker equipped with a caterpillar-type wheel was designed to enable the elderly to safely walk in all three terrains. As shown in Figure 1, the caterpillar-type walker, with a height of $870 \mathrm{~mm}$, a width of $580 \mathrm{~mm}$, a length of $680 \mathrm{~mm}$, and a weight of $40 \mathrm{~kg}$, consisted of a driving part and a control part. 


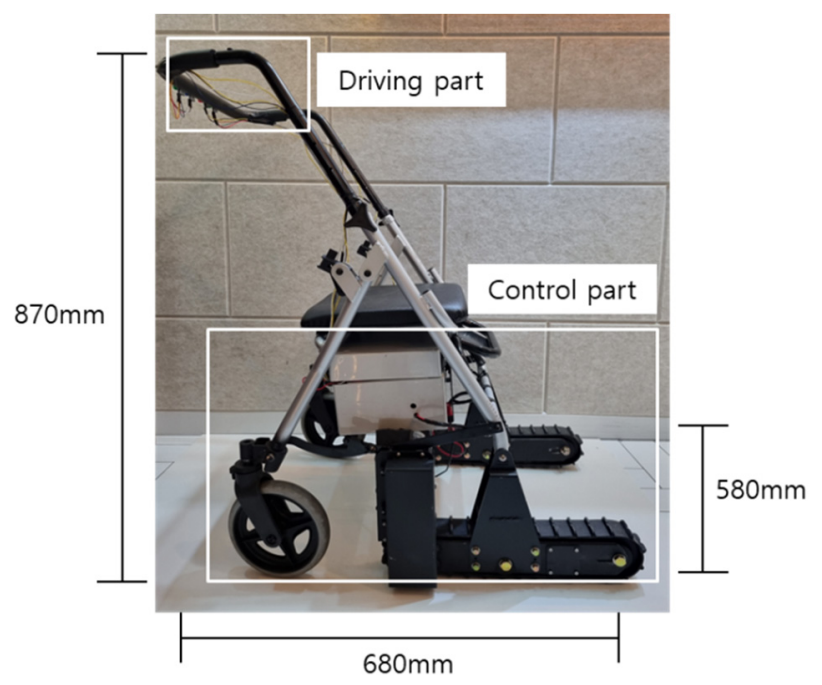

Figure 1. Caterpillar-type walker.

\subsection{Driving Part}

The circular wheels used in the existing walkers can be pushed on sloped terrain even with the brakes due to their low friction. In uneven terrain, if the wheels collides with an obstacle, it may cause a user to fall. Therefore, in this study, the driving unit was designed based on the following specific goals. (1) The walker should not slide backward on the uphill slope or go forward on the downhill slope. (2) It must be able to drive on uneven terrain with gravel or dents without the wheels jamming or falling out. (3) It should easily overcome the different heights of obstacles with little effort. (4) Even if the user's weight is placed on the back of the walker, it should not fall backward.

As shown in Figure 2, the driving unit consists of a caterpillar, DC motor, central control unit, motor controller, and battery. The caterpillars were installed on the front wheels of the walker to prevent the wheels from falling out or getting caught between obstacles, even in uneven terrain. As shown in Figure 3, it was designed with a height of $100 \mathrm{~mm}$, a width of $50 \mathrm{~mm}$, a length of $450 \mathrm{~mm}$, and with 32 links. The height of the caterpillar was set to $100 \mathrm{~mm}$ so that the user could walk without getting caught on obstacles. In addition, considering the direction change and mobility of the walker, the width and length of the caterpillar were set to $50 \mathrm{~mm}$ and $450 \mathrm{~mm}$, respectively, using Equations (1) and (2) regarding the ground pressure.

$$
\begin{gathered}
\mathrm{P}=\frac{W}{2 \times w(L)} \\
\mathrm{L}=\mathrm{A}+(\mathrm{B}-\mathrm{A}) \times 0.35
\end{gathered}
$$

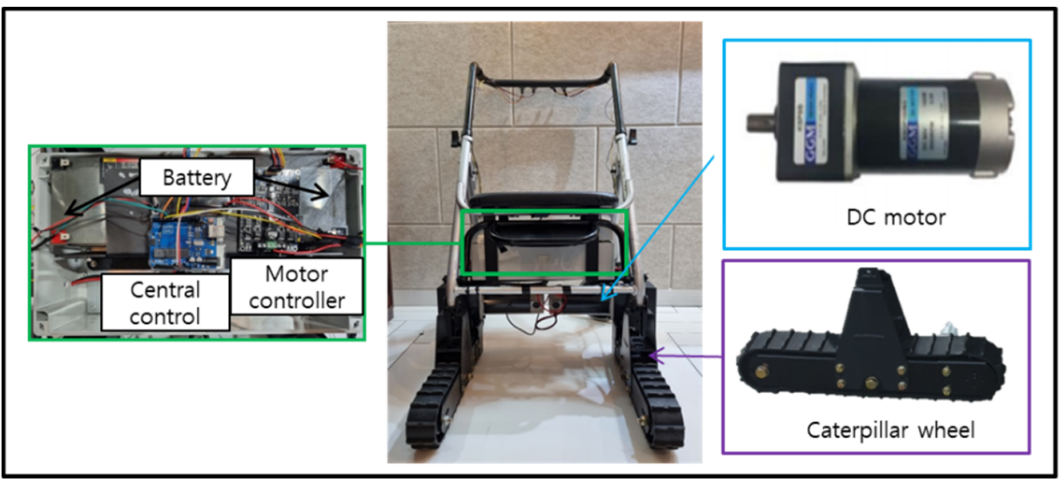

Figure 2. Driving part of caterpillar-type walker. 


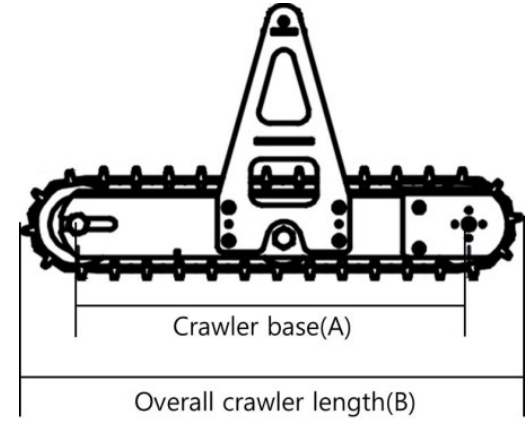

(a)

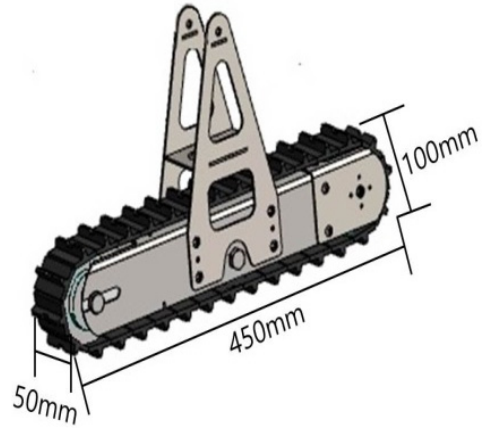

(b)

Figure 3. (a) Flat caterpillar, (b) 3D caterpillar.

Table 1 shows the characteristics of the caterpillar. The caterpillar was made of a circular frame with high stability due to its evenly distributed load and low center of gravity, and SM25C (carbon steel for mechanical structures) was used to support the overall weight of the walker and the user's pressure. To minimize noise and vibration, ethylene propylene diene rubber was used as the orbital material. Irregularities were applied to the orbit in consideration of mobility in uneven terrain or obstacle terrain and slippage in sloped terrain. The sprocket that provides power to the caterpillar is located in the rear, and an idler-wheel is formed in the front to prevent deviation of the caterpillar.

Table 1. Caterpillar specifications.

\begin{tabular}{cc}
\hline Item & Specification \\
\hline Caterpillar size & $100 \times 50 \times 45$ \\
Frame material & SM25C \\
Track material & Ethylene propylene diene rubber \\
\hline
\end{tabular}

To prevent the front wheel from lifting when the user's weight is placed on the back of the walker, a caterpillar is installed only on the front. A circular wheel was used in the rear part for smooth direction change when walking. DC motors (DS-400, GGM, Seoul, Korea) were mounted to stably drive the caterpillar in various terrains, and the deceleration ratio was set to $1: 12.5$ to generate a torque of $3.55 \mathrm{~N} \cdot \mathrm{m}$ in one wheel. The central control unit (Arduino uno (R3), Arduino, MA, USA) and the motor controller (MDD10A, Cytron, Pulau Pinang, Malaysia) were used to control the speed of the motor and change the direction of the walker. To convert the positive and negative electrodes connected to the motor for forward and backward motions of the walker, the wiring connected to the motor was divided into two and connected to the motor controller. Through the operation unit input value, the cathode and anode were converted by the central control unit, subsequently enabling conversion of forward and backward motion. Two batteries (ATRASBX KB 12-12, ATRASBX, Seongnam, Korea) were mounted to supply stable power for more than $2 \mathrm{~h}$, even with continuous use. In addition, a control box for a central control unit, motor controller, and batteries, were manufactured to protect the system from external impact.

\subsection{Control Part}

For the easy and intuitive operation of the elderly, the control unit was composed of 4 buttons, as shown in Figure 4 . When the green button on the left or right side is pressed, it rotates in the corresponding direction, and when two green buttons are pressed at the same time, it moves in a straight direction without rotation. The blue button located on the left side is used to set the speed of the caterpillar, and the speed can be adjusted from 1 to $3 \mathrm{~km} / \mathrm{h}$. In addition, a slow start function that slowly accelerates the motor of the walker was applied for the safety of the elderly. The red button located on the right side was used to set the direction of movement of the caterpillar to forward or backward. 


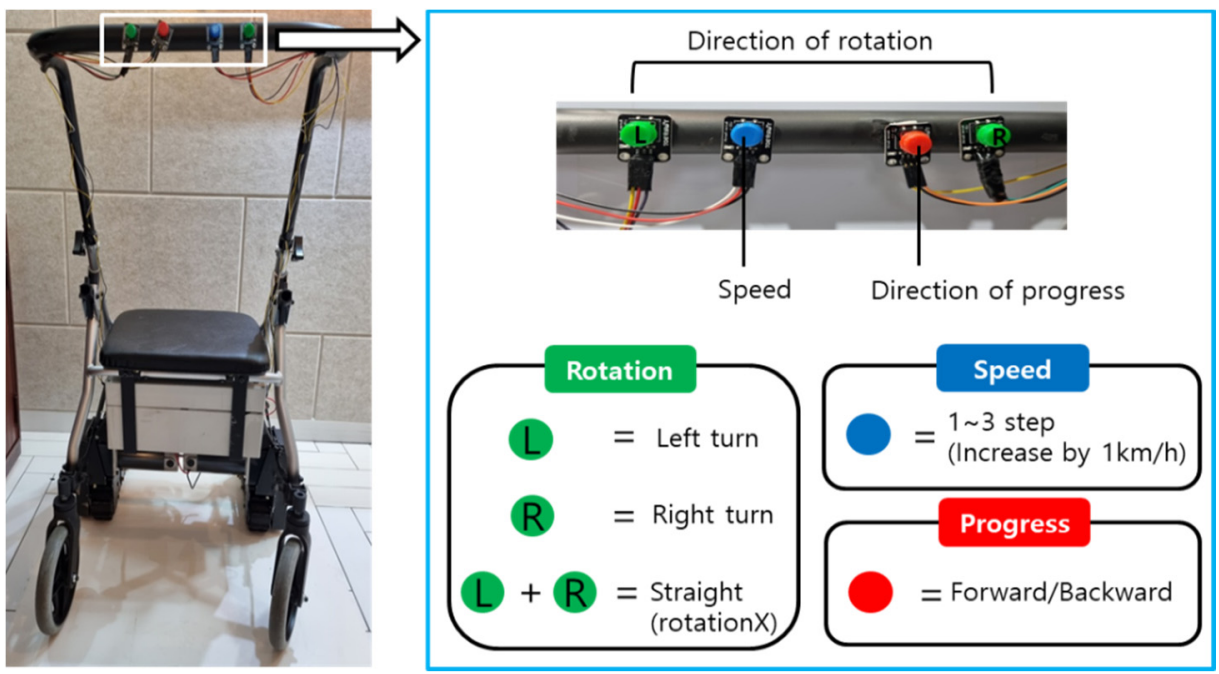

Figure 4. Control part of caterpillar-type walker.

\subsection{Experimental Method}

\subsubsection{Participants}

This study recruited senior citizens aged 65 or older registered at the K Senior Welfare Center in Jeonju. With the exclusion of those unable to walk alone or properly implement experimental instructions due to congenital or acquired disorders, the experiment was conducted on 12 elderly (5 males and 7 females) persons who can walk alone but sometimes use a walker for walking convenience. All participants received a full explanation about the experimental procedure beforehand and gave their written consent. Table 2 shows the demographic characteristics of the study subjects.

Table 2. Subject characteristics.

\begin{tabular}{cc}
\hline Characteristics & Subjects \\
\hline Sex (Male:Female) & $5: 7$ \\
Age (Years) & $77.08 \pm 5.06$ \\
Height (cm) & $164.83 \pm 7.67$ \\
Weight $(\mathrm{kg})$ & $62.75 \pm 9.06$ \\
\hline
\end{tabular}

\subsubsection{Experimental Methods and Procedures}

After measuring the static stability of the developed walker, usability was evaluated under experimental conditions similar to an actual walking environment. Static stability was measured by applying standards of angles of a forward, backward, and sideways stability test in the rollators part of ISO (ISO 11199-2). The slope specifications in ISO for each stability test are forward 15 degrees, backward 7 degrees, and sideways 3.5 degrees. However, the slope specifications used in this study were forward 20 degrees, backward 15 degrees, and sideways 10 degrees so that the stability of the walker in the terrain with higher slopes could be confirmed. To construct experimental conditions similar to the actual walking environment, uneven, obstacle, and sloped terrain were produced, as shown in Figure 5. The uneven terrain was constructed by installing a total of 8 mats with gravel, $1.5 \mathrm{~m}$ in length and $0.8 \mathrm{~m}$ in width, on the left, right, and along both sides of the $10 \mathrm{~m}$ long walking path. In the obstacle terrain, obstacles with a height difference of $1 \mathrm{~cm}$ were installed at intervals of $2 \mathrm{~m}$ on a walking path having a total length of $6 \mathrm{~m}$. The sloped terrain had a total length of $4.5 \mathrm{~m}$, and the angle of the ramp was set to 10 degrees or 20 degrees to evaluate the effect of the angle difference. In addition, the number of obstacles overcome by each walker in the obstacle terrain was measured, and the test administrator counted the overcome obstacles. The walking speed was calculated by averaging the time taken to traverse each terrain and measured by stopwatch. 


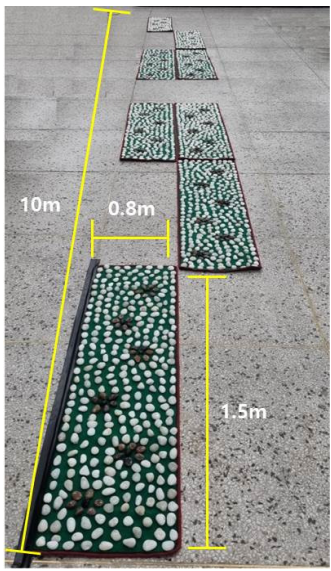

(a)

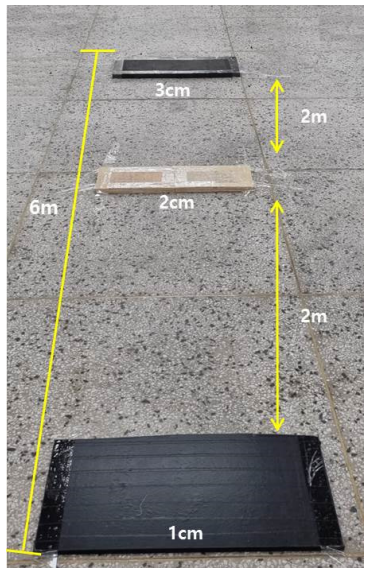

(b)

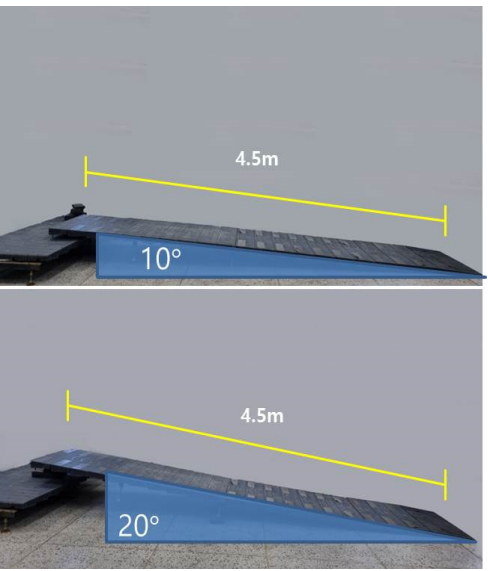

(c)

Figure 5. (a) Uneven terrain; (b) obstacle terrain; (c) sloped terrain.

To evaluate the usability of the developed walker, all subjects were asked to walk on uneven, obstacle, and sloped terrain (uphill and downhill) using a general-type walker (GTW) and a caterpillar-type walker (CTW). The upper and lower extremity muscle activity was measured with an electromyography (EMG) measurement system (MyoResearch3, Noraxon, Scottsdale, AZ, USA). The order of using the two different walkers was randomized. The two walkers used are shown in Figure 6, and in order to not affect the measurement of muscle activity, the experiments were conducted with the same height $(870 \mathrm{~mm})$.

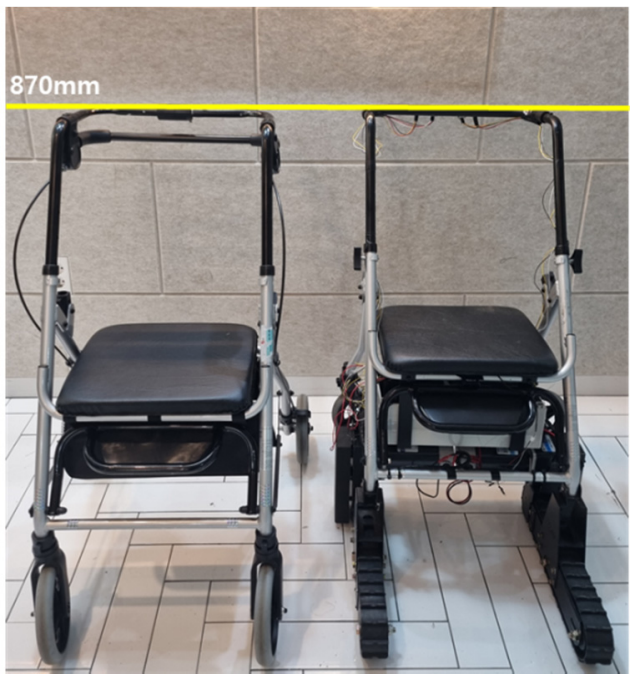

Figure 6. The general-type walker and caterpillar-type walker used in the experiment.

As shown in Figure 7, surface electrodes were attached to the muscles of the upper extremities, specifically the flexor digitorum superficialis (FDS), biceps brachii (BB), flexor digitorum profundus (FDP), triceps brachii (TB), and the lower extremity muscles, specifically the tibialis anterior (TA), rectus femoris (RF), gastrocnemius (GA), and biceps femoris (BF). To remove skin resistance, the electrode attachment area was cleaned with alcohol before the experiment. The magnitude of muscle activations was normalized using the maximum voluntary contraction (MVC). The maximum muscle strength of FDS, FDP, BB, and $\mathrm{TB}$ was measured from a sitting position, with a fixed elbow, when the wrist was pulled back and pushed forward, and when the forearm was flexed and extended. The maximum muscle strength of TA and RF was measured from a standing position with the leg extended when resisting external force applied to the ankle. The maximum muscle strength of GA was measured from a two-leg standing position with the heel raised up 
when resisting an external force acting on the shoulder. The maximum muscle strength of $\mathrm{BF}$ was measured when resisting an external force applied to the leg while supporting the wall with the hand and lifting the leg backward. The maximum strength of each muscle was measured three times in 5-s intervals while some resistance was applied. The EMG signal was measured at $1000 \mathrm{~Hz}$ after passing through a band filter $(20 \sim 400 \mathrm{~Hz})$, notch filter at $60 \mathrm{~Hz}$, rectification, and smoothing. To prevent fatigue in the upper and lower extremities, all participants were asked to take a break of $10 \mathrm{~min}$ in each experimental condition.

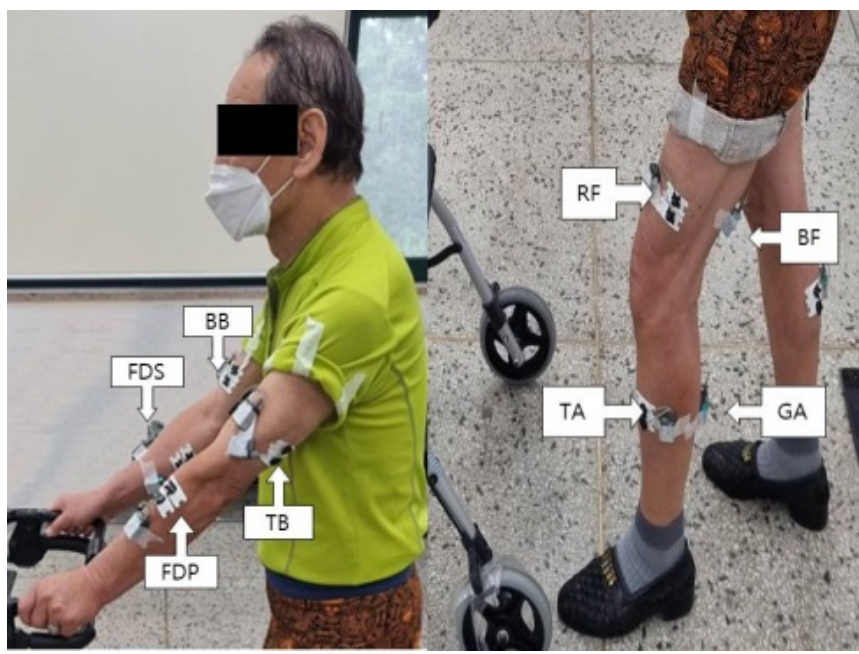

Figure 7. Electrode positioning for the measurement of upper and lower extremity muscle activity.

To evaluate the satisfaction levels with CTW and GTW, a questionnaire was produced based on QUEST2.0 (Quebec User Evaluation with Assistive Technology), a satisfaction evaluation tool for assistive devices, as shown in Table 3 [24]. Out of the total 12 possible items of QUEST2.0, the questionnaire for this study was conducted with eight items related to auxiliary equipment (dimensions, weight, adjustments, safety, durability, simplicity of use, comfort, and effectiveness), except for the four items related to service. Importance was evaluated by selecting three main items.

Table 3. Satisfaction evaluation item table.

\begin{tabular}{cc}
\hline Items \\
\hline Dimensions \\
Weight \\
Adjustments \\
Safety \\
Durability \\
Simplicity of use \\
Comfort \\
Effectiveness \\
\hline
\end{tabular}

\subsubsection{Statistical Analysis}

Statistical analysis was performed using SPSS 18.0 (IBM SPSS Statistics 18, IBM Corporation, Armonk, NY, USA). A Wilcoxon signed-rank test was performed to compare differences in the activities of upper and lower extremity muscles activity, the number of overcome obstacles, and walking time in each experimental condition. In addition, the activities of the upper and lower extremity muscles activity for each walker according to obstacle height and inclination angle were compared using the Kruskal-Wallis test. Finally, satisfaction was compared using Wilcoxon signed-rank test. Statistical significance was set at $p<0.05$. 


\section{Results}

\subsection{Static Stability}

Figure 8 shows the results of static stability at forward 20 degrees, backward 15 degrees, and sideways 10 degrees inclination. The CTW was stationary under all conditions, ensuring static stability. In contrast, the GTW was not stationary under all conditions, so static stability was not guaranteed in this case.

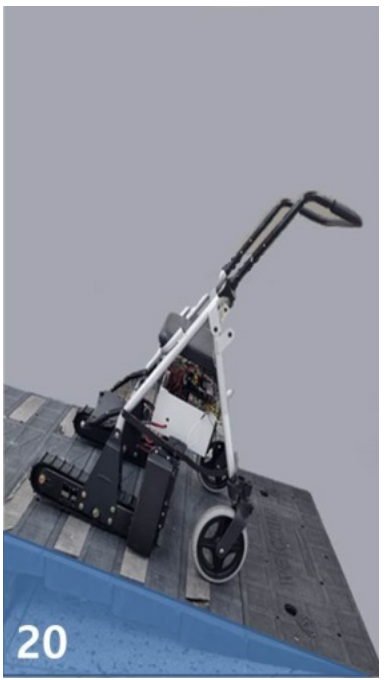

(a)

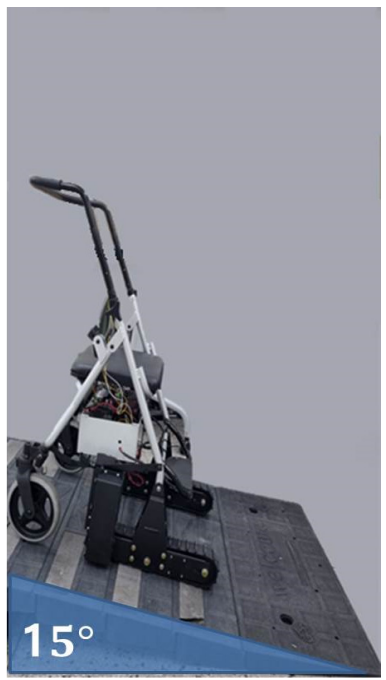

(b)

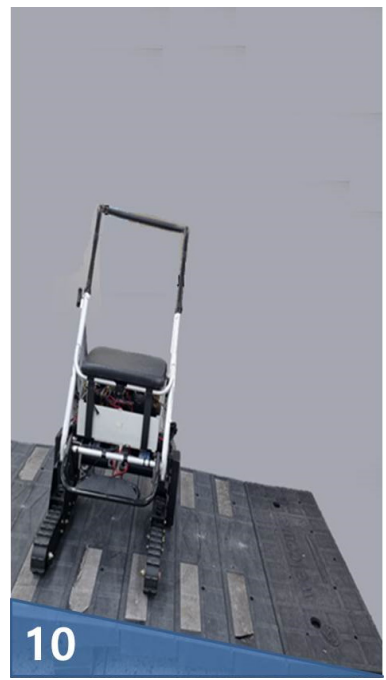

(c)

Figure 8. (a) Forward stability test; (b) backward stability test; (c) sideways stability test.

\subsection{Upper and Lower Extremity Muscle Activity}

\subsubsection{Uneven Terrain}

Table 4 shows activity in the upper and lower extremity muscles when walking on uneven terrain. When the CTW was used, there were reductions of $26 \%$ in FDS, $24 \%$ in $\mathrm{BB}, 13 \%$ in FDP, $26 \%$ in TB, $21 \%$ in $\mathrm{TA}, 16 \%$ in $\mathrm{RF}, 31 \%$ in GA, and $21 \%$ in BF in the upper and lower extremities activity compared to when using the GTW. Wilcoxon signed-rank test showed that there was a statistical difference in muscle activity under these conditions $(p<0.05)$.

Table 4. Upper and lower extremity muscle activity in uneven terrain.

\begin{tabular}{|c|c|c|c|c|c|c|c|c|}
\hline & FDS & BB & FDP & ТВ & TA & RF & GA & BF \\
\hline GTW & $\begin{array}{c}16.51 \pm 3.5 \\
(14.7,13.1-18.8)\end{array}$ & $\begin{array}{c}11.43 \pm 3.4 \\
(10.3,7.3-14.4)\end{array}$ & $\begin{array}{c}34.07 \pm 4.3 \\
(33.1,26.8-43.8)\end{array}$ & $\begin{array}{c}28.38 \pm 4.5 \\
(27.2,23.1-33.2)\end{array}$ & $\begin{array}{c}23.11 \pm 2.5 \\
(22.3,17.9-26.7)\end{array}$ & $\begin{array}{c}23.95 \pm 2.7 \\
(22.9,16.5-27.9)\end{array}$ & $\begin{array}{c}26.01 \pm 3.5 \\
(24.5,19.7-32.1)\end{array}$ & $\begin{array}{c}27.86 \pm 4.1 \\
(27.8,20.8-34.1)\end{array}$ \\
\hline CTW & $\begin{array}{c}12.15 \pm 3.4 \\
(10.8,6.9-16.2) *\end{array}$ & $\begin{array}{c}8.58 \pm 4.1 \\
(7.8,5.5-10.1)\end{array}$ & $\begin{array}{c}29.31 \pm 4.1 \\
(30.5,21.1-35.9) *\end{array}$ & $\begin{array}{c}20.75 \pm 5.1 \\
(20.3,14.8-35.9) *\end{array}$ & $\begin{array}{c}18.20 \pm 2.3 \\
(17.2,11.2-23.6)\end{array}$ & $\begin{array}{c}19.94 \pm 3.1 \\
(19.8,14.6-26.2) *\end{array}$ & $\begin{array}{c}17.89 \pm 2.7 \\
(17.5,13.5-20.4) *\end{array}$ & $\begin{array}{c}21.97 \pm 3.8 \\
(21.7,13.1-26.1) *\end{array}$ \\
\hline
\end{tabular}

Notes: $\left(\mathrm{M} \pm \mathrm{SD}\right.$ (median, IQR)); ${ }^{*}$ : Significant difference in the uneven terrain extremity muscle activity between when walking with GTW and walking with CTW $(p<0.05)$.

\subsubsection{Obstacle Terrain}

Table 5 and Figure 9 show the activity of the upper and lower extremity muscles using GTW and CTW in obstacle terrain. The statistical significance of the comparison of muscle activity for the two walkers was confirmed through Wilcoxon signed-rank test. Comparing the results for CTW and GTW, in the case of 1-cm-high obstacles, a reduction of $11 \%$ in FDS, $39 \%$ in $\mathrm{BB}, 2 \%$ in FDP, and $20 \%$ in TB occurred. In the case of 2-cm-high obstacles, a reduction of $40 \%$ in FDS, $61 \%$ in BB, $21 \%$ in FDP, and $48 \%$ in TB was observed. Finally, in the case of $3-\mathrm{cm}$-high obstacles, a reduction of $46 \%$ in FDS, $61 \%$ in BB, $16 \%$ in FDP, and $48 \%$ in TB occurred. These were all significant differences in the activity of the upper extremity muscles for all experimental conditions between GTW and CTW $(p<0.05)$. The 
statistical significance of muscle activity according to obstacle height for the two walkers was confirmed through a Kruskal-Wallis test. When using GTW, significant increases in muscle activity occurred as the obstacle height increased to $1-2 \mathrm{~cm}, 2-3 \mathrm{~cm}$, and 1-3 cm, respectively. The increases of $28 \%, 41 \%, 35 \%$ in FDS, 36\%, 41\%, 35\% in BB, 20\%, 13\%, 22\% in FDP, and 36\%, 45\%, 39\% in TB were observed. As the obstacle height increased, the activity of all upper extremity muscles increased significantly $(p<0.05)$. When using CTW, the activity of FDS muscle decreased by 5\%,1\%, and 7\% as the obstacle height increased to $1-2 \mathrm{~cm}, 2-3 \mathrm{~cm}, 1-3 \mathrm{~cm}$, respectively. In contrast, in the case of BB, FDP, and TB, the increases in muscle activity occurred as the obstacle height increased to $1-2 \mathrm{~cm}, 2-3 \mathrm{~cm}$, and $1-3 \mathrm{~cm}$, respectively. The increase of $1 \%, 7 \%, 8 \%$ in BB, $1 \%, 5 \%, 7 \%$ in FDP, and $1 \%, 5 \%$, $7 \%$ in TB was observed. The observed differences were not statistically significant.

Comparing the results for CTW and GTW, in the case of 1-cm-high obstacles, a reduction of $15 \%$ in TA, $12 \%$ in RF, $9 \%$ in GA, and $42 \%$ in BF occurred. In the case of 2-cm-high obstacles, a reduction of $42 \%$ in TA, $15 \%$ in RF, $21 \%$ in GA, and $24 \%$ in BF was observed. Finally, in the case of 3 -cm-high obstacles, a reduction of $42 \%$ in TA, $15 \%$ in RF, $28 \%$ in GA, and $24 \%$ in BF occurred. These were all significant differences in the activity of the lower extremity muscles for all experimental conditions between GTW and CTW, except in the case of BF and RF at heights of $1 \mathrm{~cm}(p<0.05)$. When using GTW, the increases in muscle activity occurred as the obstacle height increased to $1-2 \mathrm{~cm}, 2-3 \mathrm{~cm}$, and 1-3 cm, respectively. The increases of $31 \%, 37 \%, 36 \%$ in TA, 15\%, 20\%, 23\% in GA, 5\%, 14\%, 5\% in RF, and 14\%, 20\%, 18\% in BF, occurred, respectively. As the obstacle height increased, the activity of the lower extremity muscles overall increased significantly $(p<0.05)$. In contrast, when using CTW, there was a slight increase in muscle activity with obstacle heights of $1-2 \mathrm{~cm}, 2-3 \mathrm{~cm}$, and $1-3 \mathrm{~cm}$, respectively. The increases of $0.02 \%, 7 \%, 6 \%$ in TA, $1 \%, 1 \%, 2 \%$ in RF, $2 \%, 1 \%, 3 \%$ in GA, and $0.01 \%$, and $4 \%, 4 \%$ in BF were observed. There was no significant difference in the lower extremity muscle activity according to the height difference.

Table 5. Upper and lower extremity muscle activity in obstacle terrain ( $\mathrm{M} \pm \mathrm{SD}$ (median, IQR)).

\begin{tabular}{|c|c|c|c|c|c|c|}
\hline & \multicolumn{2}{|c|}{$1 \mathrm{~cm}$} & \multicolumn{2}{|c|}{$2 \mathrm{~cm}$} & \multicolumn{2}{|c|}{$3 \mathrm{~cm}$} \\
\hline & GTW & CTW & GTW & CTW & GTW & CTW \\
\hline FDS & $\begin{array}{c}14.41 \pm 2.4 \\
(14.5,11.9-16.7)\end{array}$ & $\begin{array}{c}12.80 \pm 2.7 \\
(11.5,8.9-15.3)\end{array}$ & $\begin{array}{c}20.28 \pm 2.5 \\
(19.1,13.4-25.9)\end{array}$ & $\begin{array}{c}12.12 \pm 2.8 \\
(11.5,8.9-15.3)\end{array}$ & $\begin{array}{c}22.17 \pm 2.6 \\
(20.8,16.1-26.0)\end{array}$ & $\begin{array}{c}11.95 \pm 2.8 \\
(11.09,7.0-15.1)\end{array}$ \\
\hline BB & $\begin{array}{c}10.23 \pm 3.4 \\
(11.3,8.4-13.7)\end{array}$ & $\begin{array}{c}6.19 \pm 2.4 \\
(4.8,3.4-8.1)\end{array}$ & $\begin{array}{c}16.18 \pm 3.1 \\
(16.5,13.2-18.6)\end{array}$ & $\begin{array}{c}6.29 \pm 2.7 \\
(4.8,3.4-8.1)\end{array}$ & $\begin{array}{c}17.68 \pm 2.5 \\
(15.6,10.1-23.8)\end{array}$ & $\begin{array}{c}6.78 \pm 2.7 \\
(6.9,4.5-9.0)\end{array}$ \\
\hline FDP & $\begin{array}{c}19.34 \pm 2.1 \\
(19.3,14.9-22.7)\end{array}$ & $\begin{array}{c}18.8 \pm 3.1 \\
(14.7,18.5-21.5)\end{array}$ & $\begin{array}{c}24.23 \pm 3.1 \\
(24.5,18.0-29.3)\end{array}$ & $\begin{array}{c}19.03 \pm 4.1 \\
(18.6,14.8-21.5)\end{array}$ & $\begin{array}{c}24.92 \pm 2.7 \\
(24.6,19.7-30.2)\end{array}$ & $\begin{array}{c}20.84 \pm 4.1 \\
(21.0,16.6-24.1)\end{array}$ \\
\hline TB & $\begin{array}{c}13.92 \pm 3.7 \\
(14.1,11.7-16.6)\end{array}$ & $\begin{array}{c}11.09 \pm 3.5 \\
(9.0,5.7-16.8)\end{array}$ & $\begin{array}{c}21.81 \pm 3.8 \\
(22.1,18.4-26.3)\end{array}$ & $\begin{array}{c}11.28 \pm 4.5 \\
(9.5,5.8-16.7)\end{array}$ & $\begin{array}{c}23.19 \pm 3.8 \\
(22.42,20.2-26.3)\end{array}$ & $\begin{array}{c}11.94 \pm 4.5 \\
(11.9,8.57-14.9)\end{array}$ \\
\hline TA & $\begin{array}{c}12.29 \pm 3.4 \\
(12.1,10.4-14.8)\end{array}$ & $\begin{array}{c}10.37 \pm 2.8 \\
(9.8,6.1-12.8)\end{array}$ & $\begin{array}{c}17.89 \pm 4.1 \\
(17.7,15.9-19.4) \\
\end{array}$ & $\begin{array}{c}10.34 \pm 4.1 \\
(10.0,6.2-12.8)\end{array}$ & $\begin{array}{c}19.22 \pm 4.1 \\
(18.6,14.1-24.4)\end{array}$ & $\begin{array}{c}14.73 \pm 4.1 \\
(13.5,13.1-16.1)\end{array}$ \\
\hline $\mathrm{RF}$ & $\begin{array}{c}16.40 \pm 4.1 \\
(16.3,14.9-18.7)\end{array}$ & $\begin{array}{c}14.38 \pm 2.7 \\
(14.3,9.1-18.5)\end{array}$ & $\begin{array}{c}17.32 \pm 4.5 \\
(16.6,12.5-21.3)\end{array}$ & $\begin{array}{c}14.56 \pm 4.3 \\
(14.38,9.2-18.4)\end{array}$ & $\begin{array}{c}17.33 \pm 4.5 \\
(18.24,12.97-21.0)\end{array}$ & $\begin{array}{c}15.68 \pm 4.3 \\
(14.6,11.6-19.5)\end{array}$ \\
\hline GA & $\begin{array}{c}16.6 \pm 2.8 \\
(16.9,13.7-20.6)\end{array}$ & $\begin{array}{c}15.1 \pm 3.1 \\
(13.2,15.1-19.1)\end{array}$ & $\begin{array}{c}19.62 \pm 3.4 \\
(19.4,15.9-22.9)\end{array}$ & $\begin{array}{c}15.45 \pm 2.4 \\
(15.0,12.0-19.1)\end{array}$ & $\begin{array}{c}21.82 \pm 3.4 \\
(20.3,17.8-24.4)\end{array}$ & $\begin{array}{c}16.17 \pm 2.4 \\
(15.5,12.1-19.5)\end{array}$ \\
\hline $\mathrm{BF}$ & $\begin{array}{c}17.5 \pm 3.4 \\
(17.4,15.4-20.8)\end{array}$ & $\begin{array}{c}15.45 \pm 4.1 \\
(14.2,10.1-19.8)\end{array}$ & $\begin{array}{c}20.46 \pm 3.5 \\
(19.6,17.1-23.8)\end{array}$ & $\begin{array}{c}15.42 \pm 2.5 \\
(14.29,10.2-19.5)\end{array}$ & $\begin{array}{c}21.48 \pm 3.5 \\
(22.1,15.1-26.1)\end{array}$ & $\begin{array}{c}17.2 \pm 22.5 \\
(16.9,12.5-20.2)\end{array}$ \\
\hline
\end{tabular}




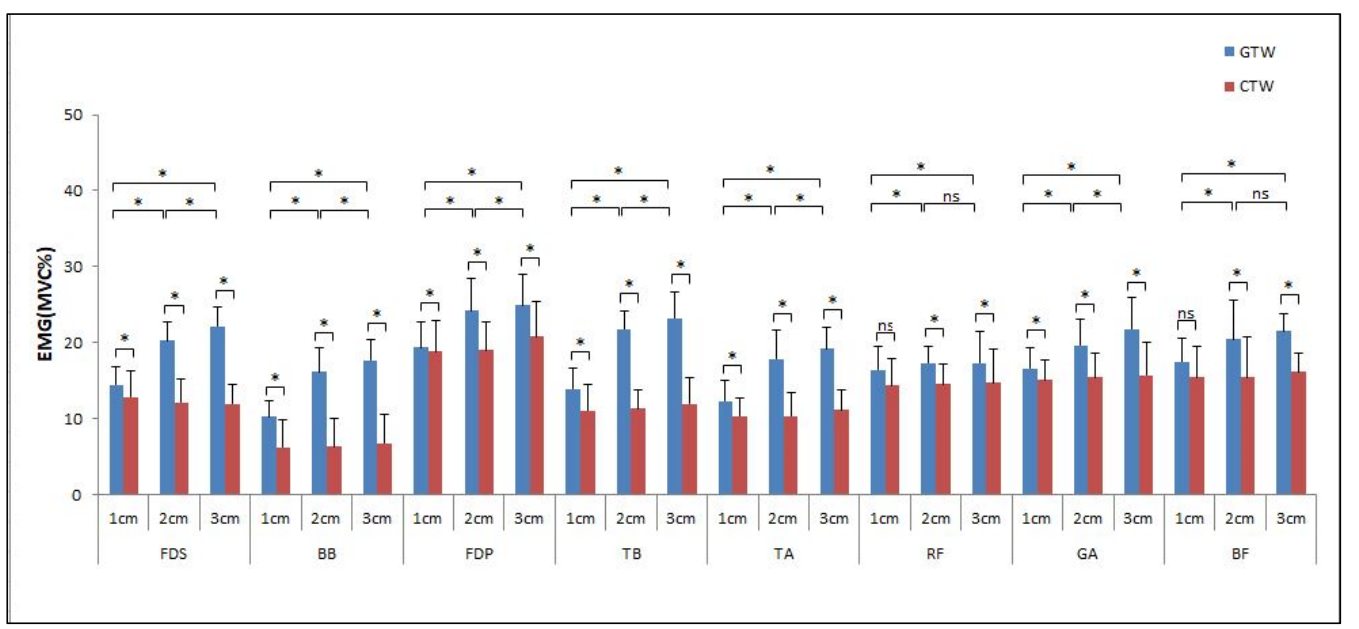

Figure 9. Upper and lower extremity muscle activity in obstacle terrain $\left({ }^{\mathrm{ns}}\right.$ not significant, ${ }^{*}$ significant difference $(p<0.05))$.

\subsubsection{Sloped Terrain}

Table 6 shows the activity of the upper extremity and lower extremity muscles when using GTW and CTW in sloped terrain. The statistical significance of muscle activity for each condition was confirmed through Wilcoxon signed-rank test. In the uphill section, on a 10-degree inclination angle, a reduction of $2 \%$ in FDS, $14 \%$ in BB, $17 \%$ in FDP, $24 \%$ in TB, $25 \%$ in TA, $15 \%$ in RF, $20 \%$ in GA, and $22 \%$ in BF occurred when using CTW compared to GTW. Significant differences were observed in FDP, TB, TA, RF, GA, and BF $(p<0.05)$. On a 20 -degree inclination angle, a reduction of $2 \%$ in FDS, $10 \%$ in BB, $17 \%$ in FDP, $25 \%$ in TB, $25 \%$ in TA, $14 \%$ in RF, $21 \%$ in GA, and $24 \%$ in BF occurred when using CTW compared to GTW. Significant differences were observed in FDP, TB, TA, RF, GA, and BF ( $p<0.05)$. Additionally, the statistical significance of muscle activity according to inclination angle for the two walkers was confirmed through a Kruskal-Wallis test. In the case of GTW, when the inclination angle increased from 10 degrees to 20 degrees, the muscle activity increased by $2 \%$ in FDS, $9 \%$ in BB, $8 \%$ in FDP, $8 \%$ in TB, $15 \%$ in TA, $18 \%$ in RF, $7 \%$ in GA, and $8 \%$ in $\mathrm{BF}$. In the case of CTW, the muscle activity increased by $2 \%$ in FDS, $13 \%$ in BB, $8 \%$ in FDP, $6 \%$ in $\mathrm{TB}, 13 \%$ in $\mathrm{TA}, 19 \%$ in $\mathrm{RF}, 6 \%$ in GA, and $5 \%$ in BF. A significant difference was only observed in the TB muscle $(p<0.05)$.

In the downhill section, on a 10-degree inclination angle, a reduction of $15 \%$ in FDS, $33 \%$ in $\mathrm{BB}, 2 \%$ in FDP, $11 \%$ in $\mathrm{TB}, 18 \%$ in $\mathrm{TA}, 14 \%$ in $\mathrm{RF}, 20 \%$ in $\mathrm{GA}$, and $14 \%$ in $\mathrm{BF}$ occurred when using CTW compared to GTW. Significant differences were observed in FDS, BB, TA, $\mathrm{RF}, \mathrm{GA}$, and BF muscles $(p<0.05)$. On a 20-degree inclination angle, a reduction of $26 \%$ in FDS, $49 \%$ in BB, $3 \%$ in FDP, $10 \%$ in TB, $29 \%$ in TA, $14 \%$ in RF, $22 \%$ in GA, and $14 \%$ in BF were observed when using CTW compared to GTW. Significant differences were observed in FDS, BB, TA, RF, GA, and BF muscles $(p<0.05)$. Additionally, in the case of GTW, when the angle increased from 10 degrees to 20 degrees, the muscle activity increased by $11 \%$ in FDS, $25 \%$ in $\mathrm{BB}, 5 \%$ in $\mathrm{FDP}, 2 \%$ in $\mathrm{TB}, 11 \%$ in $\mathrm{TA}, 2 \%$ in $\mathrm{RF}, 5 \%$ in $\mathrm{GA}$ and $0.6 \%$ in $\mathrm{BF}$. In the case of CTW, the muscle activity decreased by $2 \%$ in FDS and $0.3 \%$ in TA while it increased by $2 \%$ in BB, $4 \%$ in $\mathrm{FDP}, 2 \%$ in TB, $2 \%$ in $\mathrm{RF}, 4 \%$ in GA, and $2 \%$ in $\mathrm{BF}$. A significant difference was only observed in the cases of BB and FDP muscles $(p<0.05)$. 
Table 6. Upper and lower extremity muscle activity in sloped terrain.

\begin{tabular}{|c|c|c|c|c|c|c|c|c|}
\hline & \multicolumn{4}{|c|}{ Uphill } & \multicolumn{4}{|c|}{ Downhill } \\
\hline & \multicolumn{2}{|c|}{$10^{\circ}$} & \multicolumn{2}{|c|}{$20^{\circ}$} & \multicolumn{2}{|c|}{$10^{\circ}$} & \multicolumn{2}{|c|}{$20^{\circ}$} \\
\hline & GTW & CTW & GTW & CTW & GTW & CTW & GTW & CTW \\
\hline FDS & $\begin{array}{c}13.80 \pm 2.55 \\
(12.9,9.9-16.8)\end{array}$ & $\begin{array}{c}13.46 \pm 3.65 \\
(12.7,6.7-18.3)\end{array}$ & $\begin{array}{c}14.21 \pm 3.75 \\
(14.0,12.1-16.0)\end{array}$ & $\begin{array}{c}13.86 \pm 2.77 \\
(13.7,11.4-16.7)\end{array}$ & $\begin{array}{c}13.69 \pm 1.56 \\
(13.6,10.8-15.9)\end{array}$ & $\begin{array}{c}11.50 \pm 1.63 \\
(10.0,5.5-15.4)\end{array}$ & $\begin{array}{c}15.39 \pm 2.53 \\
(15.7,12.8-17.1)\end{array}$ & $\begin{array}{c}11.25 \pm 2.31 \\
(10.5,6.8-14.5)^{*}\end{array}$ \\
\hline BB & $\begin{array}{c}6.28 \pm 1.36 \\
(5.6,4.4-7.8)\end{array}$ & $\begin{array}{c}5.39 \pm 1.32 \\
(5.1,3.6-6.8)\end{array}$ & $\begin{array}{c}6.96 \pm 1.23 \\
(6.9,4.7-8.7)\end{array}$ & $\begin{array}{c}6.24 \pm 1.68 \\
(5.0,10.6-22.2)\end{array}$ & $\begin{array}{c}6.53 \pm 2.12 \\
(5.5,3.9-9.7)\end{array}$ & $\begin{array}{c}4.34 \pm 1.47 \\
(3.8,2.4-6.0) *\end{array}$ & $\begin{array}{c}8.80 \pm 1.21 \\
(8.1,5.5-12.0)^{\#}\end{array}$ & $\begin{array}{c}4.46 \pm 1.73 \\
(3.9,2.3-6.4)^{*}\end{array}$ \\
\hline FDP & $\begin{array}{c}18.36 \pm 3.21 \\
(16.9,15.5-20.2) \\
\end{array}$ & $\begin{array}{c}15.19 \pm 2.55 \\
(13.9,11.3-18.3) *\end{array}$ & $\begin{array}{c}20.09 \pm 4.75 \\
(20.0,12.7-25.7)\end{array}$ & $\begin{array}{c}16.57 \pm 2.37 \\
(15.8,10.6-22.2)\end{array}$ & $\begin{array}{c}18.57 \pm 3.54 \\
(17.4,14.5-21.8) \\
\end{array}$ & $\begin{array}{c}18.08 \pm 3.55 \\
(16.9,9.9-23.8)\end{array}$ & $\begin{array}{c}19.67 \pm 3.52 \\
(19.4,16.2-23.0)^{\#}\end{array}$ & $\begin{array}{c}18.98 \pm 2.61 \\
(18.9,13.0-26.1)\end{array}$ \\
\hline TB & $\begin{array}{c}20.40 \pm 2.25 \\
(17.8,15.2-25.7) \\
\end{array}$ & $\begin{array}{c}15.38 \pm 3.21 \\
(14.3,12.5-18.6) *\end{array}$ & $\begin{array}{c}22.20 \pm 2.52 \\
(21.2,17.9-25.2)\end{array}$ & $\begin{array}{c}16.51 \pm 2.05 \\
(16.6,16.3-18.8)\end{array}$ & $\begin{array}{c}14.37 \pm 2.34 \\
(14.8,10.8-17.4)\end{array}$ & $\begin{array}{c}12.75 \pm 3.25 \\
(11.8,10.5-17.2)\end{array}$ & $\begin{array}{c}14.69 \pm 2.04 \\
(14.7,11.3-17.7)\end{array}$ & $\begin{array}{c}13.11 \pm 1.68 \\
(12.3,10.4-15.1)\end{array}$ \\
\hline TA & $\begin{array}{c}20.06 \pm 2.72 \\
(19.2,15.2-25.3)\end{array}$ & $\begin{array}{c}15.04 \pm 3.41 \\
(14.6,11.4-19.1)^{*}\end{array}$ & $\begin{array}{c}23.60 \pm 2.57 \\
(22.9,19.5-25.2)\end{array}$ & $\begin{array}{c}17.48 \pm 3.13 \\
(17.2,11.4-20.6) *\end{array}$ & $\begin{array}{c}15.14 \pm 3.55 \\
(14.7,9.2-18.5)\end{array}$ & $\begin{array}{c}12.41 \pm 2.56 \\
(11.5,6.9-16.6)\end{array}$ & $\begin{array}{c}17.06 \pm 2.64 \\
(16.7,13.6-18.8)\end{array}$ & $\begin{array}{c}12.03 \pm 3.12 \\
(12.4,7.1-16.3)\end{array}$ \\
\hline RF & $\begin{array}{c}19.93 \pm 3.41 \\
(20.7,14.6-25.1)\end{array}$ & $\begin{array}{c}16.90 \pm 3.13 \\
(17.21,10.8-20.2) *\end{array}$ & $\begin{array}{c}24.58 \pm 4.41 \\
(23.5,19.6-29.2)\end{array}$ & $\begin{array}{c}20.94 \pm 2.12 \\
(19.7,14.1-29.2) *\end{array}$ & $\begin{array}{c}24.00 \pm 4.14 \\
(23.1,18.2-32.1)\end{array}$ & $\begin{array}{c}20.46 \pm 3.11 \\
(19.8,12.5-28.1) *\end{array}$ & $\begin{array}{c}24.54 \pm 2.82 \\
(25.7,17.7-31.0)\end{array}$ & $\begin{array}{c}21.06 \pm 3.31 \\
(20.8,16.3-23.2) *\end{array}$ \\
\hline GA & $\begin{array}{c}23.44 \pm 2.22 \\
(22.1,16.9-29.1)\end{array}$ & $\begin{array}{c}18.70 \pm 3.34 \\
(17.4,14.7-20.3) *\end{array}$ & $\begin{array}{c}25.34 \pm 3.05 \\
(24.8,21.2-28.4)\end{array}$ & $\begin{array}{c}19.90 \pm 2.81 \\
(19.7,17.2-22.8) \text { * }\end{array}$ & $\begin{array}{c}23.04 \pm 2.35 \\
(22.4,18.9-26.1)\end{array}$ & $\begin{array}{c}18.24 \pm 2.25 \\
(17.7,14.1-20.1) \text { * }\end{array}$ & $\begin{array}{c}24.49 \pm 2.14 \\
(23.7,21.6-27.4)\end{array}$ & $\begin{array}{c}19.01 \pm 2.04 \\
(18.2,16.2-21.1) *\end{array}$ \\
\hline $\mathrm{BF}$ & $\begin{array}{c}22.75 \pm 2.35 \\
(23.1,18.3-27.1)\end{array}$ & $\begin{array}{c}17.70 \pm 3.44 \\
(17.4,14.7-20.3) \text { * }\end{array}$ & $\begin{array}{c}24.75 \pm 3.1 \\
(23.5,21.3-29.1)\end{array}$ & $\begin{array}{c}18.80 \pm 3.61 \\
(17.5,14.6-22.5) \text { * }\end{array}$ & $\begin{array}{c}20.99 \pm 3.05 \\
(21.7,14.9-26.0)\end{array}$ & $\begin{array}{c}18.04 \pm 2.54 \\
(18.6,12.1-22.9)\end{array}$ & $\begin{array}{c}21.03 \pm 2.59 \\
(19.9,13.5-24.8)\end{array}$ & $\begin{array}{c}18.09 \pm 3.25 \\
(18.1,14.8-21.5) *\end{array}$ \\
\hline
\end{tabular}

Notes: $(\mathrm{M} \pm \mathrm{SD}$ (median, IQR)); *: Significant difference in the upper and lower extremity muscle activity between when walking with GTW and walking with CTW $(p<0.05)$; ${ }^{\#}$ : Significant difference in the upper and lower extremity muscle activity between the 10 degrees and 20 degrees $(p<0.05)$

\subsection{The Number of Overcome Obstacles}

When using a walker in flat terrain, there are no instances of a wheel being caught on an obstacle, inhibiting forward motion. However, in uneven terrain with obstacles, even if they are as small as $1-2 \mathrm{~cm}$, the walker is obstructed by that obstacle. Therefore, the number of obstacles that were overcome when walking was measured when using a walker in the obstacle terrain. Table 7 shows the number of overcome obstacles by section when using GTW and CTW in the obstacle terrain. The statistical significance of the number of overcome obstacles for each condition was confirmed through Wilcoxon signed-rank test. The number of overcome obstacles in the $1 \mathrm{~cm}$ section was 30 times for GTW and 36 times for CTW. In the $2 \mathrm{~cm}$ section, it was 0 times for GTW and 36 times for CTW. Finally, in the $3 \mathrm{~cm}$ section, the outcome was the same as in the $2 \mathrm{~cm}$ section. The average obstacle overcoming rate (success rate) was $27 \%$ for GTW and $100 \%$ for CTW. In all sections, there were significant differences in the number of obstacles overcome between using GTW and CTW, except in the $1 \mathrm{~cm}$ section $(p<0.05)$.

Table 7. The number of overcome obstacles in obstacle terrain.

\begin{tabular}{ccccc}
\hline & $\mathbf{1} \mathbf{c m}$ & $\mathbf{2} \mathbf{c m}$ & $\mathbf{3} \mathbf{~ c m}$ & $\begin{array}{c}\text { Average Obstacle } \\
\text { Overcoming Rate }\end{array}$ \\
\hline GTW & $30 / 36(83 \%)$ & $0 / 36(0 \%)$ & $0 / 36(0 \%)$ & $27 \%$ \\
CTW & $36 / 36(100 \%)$ & $36 / 36(100 \%) *$ & $36 / 36(100 \%) *$ & $100 \%$ \\
\hline
\end{tabular}

Notes: (\%); *: Significant difference in the number of overcame obstacles terrain between when walking with GTW and walking with CTW $(p<0.05)$.

\subsection{Walking Speed for Each Terrain}

Table 8 shows the walking speed when using GTW and CTW in each terrain. The statistical significance of walking speed for each terrain was confirmed through Wilcoxon signed-rank test. In uneven terrain, the walking speed increased by $31 \%$ when using CTW compared to GTW. In the obstacle terrain, the walking speed increased by $42 \%$ when using CTW compared to GTW. When using CTW, there was a significant increase in walking speed for both uneven terrain and obstacle terrain compared to GTW $(p<0.05)$. In sloped terrain, in the uphill section at 10 degrees, the walking speed decreased by $22 \%$ when using CTW compared to GTW. In the uphill sections at 20 degrees, it decreased by $20 \%$ when using CTW compared to GTW. In addition, in the downhill section at 10 degrees, 
the walking speed decreased by $26 \%$ when using CTW compared to GTW. In the downhill section at 20 degrees, it decreased by 7\% when using CTW compared to GTW. There were significant differences in the walking speed between using GTW and CTW in both uphill and downhill sections $(p<0.05)$.

Table 8. Walking speed in each terrain.

\begin{tabular}{cccccccc}
\hline & Uneven Terrain & $\begin{array}{c}\text { Obstacle } \\
\text { Terrain }\end{array}$ & Uphill & \multicolumn{2}{c}{ Sloped Terrain } & Downhill & 20 \\
\hline \multirow{2}{*}{ GTW } & $0.31 \pm 0.08$ & $0.26 \pm 0.05$ & $0.52 \pm 0.07$ & $0.43 \pm 0.04$ & $0.53 \pm 0.11$ & $0.44 \pm 0.01$ \\
& $(0.3,0.2-0.4)$ & $(0.2,0.1-0.3)$ & $(0.5,0.3-0.6)$ & $(0.4,0.3-0.5)$ & $(0.5,0.4-0.5)$ & $(0.4,0.4-0.6)$ \\
\hline \multirow{2}{*}{ CTW } & $0.42 \pm 0.02$ & $0.45 \pm 0.12$ & $0.40 \pm 0.08$ & $0.34 \pm 0.03$ & $0.39 \pm 0.04$ & $0.41 \pm 0.05$ \\
& $(0.4,0.3-0.4) *$ & $(0.4,0.4-0.5) *$ & $(0.4,0.3-0.4)^{*}$ & $(0.3,0.3-0.4) *$ & $(0.4,0.3-0.4)^{*}$ & $(0.4,0.3-0.4) *$ \\
\hline
\end{tabular}

Notes: $\left(\mathrm{M} \pm \mathrm{SD}\right.$ (median, IQR)); ${ }^{*}$ : Significant difference in the walking speed between when walking with GTW and walking with CTW $(p<0.05)$.

\subsection{Satisfaction}

Table 9 and Figure 10 compare satisfaction according to the use of GTW and CTW to which QUEST 2.0 is applied. The statistical significance of satisfaction for each condition was confirmed through Wilcoxon signed-rank test. The closer the score is to 5, the higher the level of satisfaction. The average overall satisfaction score was 3.95 for the GTW and 4.69 for the CTW. There was a significant difference in five items, excluding dimensions, weight, and adjustments $(p<0.05)$. In particular, satisfaction with safety, comfort, and effectiveness increased significantly when using CTW.

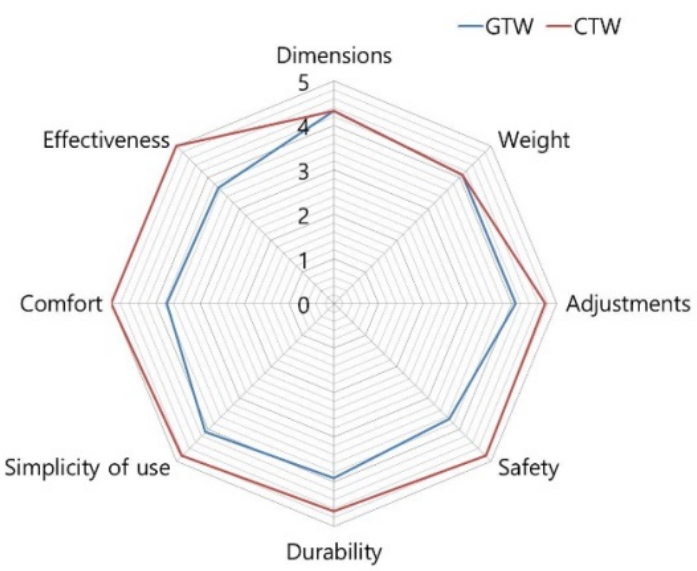

Figure 10. Satisfaction distribution. 
Table 9. Satisfaction.

\begin{tabular}{ccc}
\hline Item & GTW & CTW \\
\hline \multirow{2}{*}{ Dimensions } & $4.33 \pm 0.88$ & $4.33 \pm 1.23$ \\
& $(5,3.25-5)$ & $(5,4-5)$ \\
\hline \multirow{2}{*}{ Weight } & $4.08 \pm 0.9$ & $4.08 \pm 0.99$ \\
& $(4,3-5)$ & $(4,3.2-5)$ \\
\hline \multirow{2}{*}{ Adjustments } & $4.08 \pm 1.08$ & $4.75 \pm 0.62$ \\
& $(4.5,3-5)$ & $(5,5-5)$ \\
\hline \multirow{2}{*}{ Safety } & $3.67 \pm 0.88$ & $4.83 \pm 0.38$ \\
& $(3,3-4.7)$ & $(5,5-5)^{*}$ \\
\hline \multirow{2}{*}{ Durability } & $3.92 \pm 0.9$ & $4.67 \pm 0.65$ \\
& $(4,3-5)$ & $(5,4.2-5)^{*}$ \\
\hline \multirow{2}{*}{ Simplicity of use } & $4.08 \pm 0.99$ & $4.83 \pm 0.71$ \\
& $(4,3.2-5)$ & $(5,5-5)^{*}$ \\
\hline \multirow{2}{*}{ Comfort } & $3.75 \pm 1.13$ & $5.00 \pm 0.73$ \\
& $(4,3-5)$ & $(5,5-5)^{*}$ \\
\hline \multirow{2}{*}{ Effectiveness } & $3.67 \pm 0.98$ & $5.00 \pm 0.11$ \\
& $(3.5,3-4.7)$ & $(5,4.2-5)^{*}$ \\
\hline Average & 4.69 & 3.95
\end{tabular}

Notes: (M $\pm \mathrm{SD}$ (median, IQR)); * Significant difference in the satisfaction between when using GTW and when using CTW $(p<0.05)$.

Table 10 shows the results of internal consistency analysis between Cronbach's Alpha's satisfaction items. Cronbach's Alpha is a measure of reliability for each item as a coefficient representing consistency between items. The higher the value of the coefficient, the higher the reliability. When values between 0.8 and 0.9 appear, the reliability between items is very high. Among the Cronbach's Alpha values of item deletion, the dimensions were the highest at 0.882 , and the comfort was the lowest at 0.823 . However, since all items showed Cronbach's Alpha values of 0.8 or more, eight items were correlated with each other. In addition, as a result of the reliability evaluation between the satisfaction items of Cronbach's Alpha, it was found to be 0.814 , indicating that the evaluator's reliability was appropriate.

Table 10. Cronbach's Alpha internal agreement between satisfaction items.

\begin{tabular}{cc}
\hline Item & Cronbach's Alpha \\
\hline Dimensions & 0.882 \\
Weight & 0.869 \\
Adjustments & 0.851 \\
Safety & 0.849 \\
Durability & 0.833 \\
Simplicity of use & 0.832 \\
Comfort & 0.823 \\
Effectiveness & 0.846 \\
\hline Average & 0.814 \\
\hline
\end{tabular}

Table 11 shows the three items selected as the most important for walker based on the satisfaction evaluation results. The items of importance were effectiveness, comfort, and safety. 
Table 11. Importance of items.

\begin{tabular}{cccc}
\hline Item & Frequency & Ratio (\%) & Ranking \\
\hline Effectiveness & 12 & $33 \%$ & 1 \\
Comfort & 11 & $30 \%$ & 2 \\
Safety & 7 & $20 \%$ & 3 \\
Simplicity of use & 5 & $14 \%$ & 4 \\
Dimensions & 1 & $3 \%$ & 5 \\
Weight & 0 & $0 \%$ & 6 \\
Adjustments & 0 & $0 \%$ & 6 \\
Durability & 0 & $0 \%$ & 6 \\
\hline
\end{tabular}

\section{Discussion}

In this study, a caterpillar-type walker was developed to assist the elderly with stable walking on uneven terrain, obstacle terrain, and sloped terrain. The usability of the developed walker was evaluated by comparing the difference in the activity of the upper and lower extremities, the number of overcome obstacles, the walking speed, and satisfaction between walking with GTW and walking with CTW.

In uneven terrain, when using GTW, the activities of FDP and TB muscles were relatively larger than FDS and BB muscles. FDP is a flexor muscle used to hold an object with the hand, and TB is an extensor muscle used to extend an arm or push an object $[25,26]$. The result means that the gripping and pushing force increased when using the GTW on uneven terrain. If an elderly with weakened muscle strength uses the upper extremity muscles excessively, muscle fatigue creating biomechanical stress on structures may be caused by repetitive and excessive movements $[27,28]$. In general, when an elderly person uses a walker on flat terrain, the activity of the lower extremity muscles decreases because the weight and action applied to the lower extremities are distributed [29]. Furthermore, muscle activity increases in unbalanced terrain, indicating that it is directly related to the maintenance of body balance [30]. In the case of using a GTW equipped with circular wheels on uneven terrain, the activity in the lower extremity muscles increased as the body momentarily loses balance and the walker swaying in various directions cannot properly support the body [31]. In particular, the highest activity was shown in the GA muscle, which is activated when doing plantar flexion exercise or when the load is increased, indicating that muscles have a higher activation rate when using GTW while walking on uneven terrain [32]. The large decrease compared to other muscles means that the load on the lower extremities was significantly reduced when using CTW. In addition, the load on the sole of the foot may be reduced due to the decreased activity of the lower extremity muscles when the CTW was used. Excessive pressure can have a negative effect on the elderly foot, with increased foot muscle fatigue, foot deformity, and hard corn forming $[33,34]$. Therefore, it can be seen that the CTW can help prevent fatigue caused by the excessive use of upper extremity muscles in the elderly. In addition, reduced lower extremity muscle activity due to CTW use means that the load on the soles of the feet may be reduced. It is believed that the CTW can also help prevent these diseases. In obstacle terrain, when using the CTW, the activity of the upper extremity muscles decreased significantly, and the activities of the FDP and TB muscles were relatively larger than those of the FDS and BB muscles. Moreover, it shows that the amount of decrease in muscle activity in the $2 \mathrm{~cm}$ section was significantly higher than in the $1 \mathrm{~cm}$ section. The amount of decrease was significantly higher in the $2 \mathrm{~cm}$ section than in the $1 \mathrm{~cm}$ section because there was a tendency to push or lift the GTW more to get over the obstacle. When walking outdoors, there are sidewalk lips, and the height of the lip between the roadway and the sidewalk is $25 \mathrm{~cm}$ or less, and the height of the lip between the crosswalk and the road is $2 \mathrm{~cm}$ or less [35]. During the experiment, the GTW could not overcome the $2 \mathrm{~cm}$ ridge and collided with it, which could lead to accidents when crossing the roadway and crosswalk using a walker [36]. In the $1 \mathrm{~cm}$ obstacle section, when the CTW was used, the activity of all muscles decreased compared to when the GTW was used. However, there was no significant difference in the 
RF and BF muscles. The RF and BF muscles are the muscles mainly used to lift the leg [37]. This is because the leg is raised to push the walker with the foot in order to overcome the obstacle, there was no significant difference in RF and BF muscles in the $1 \mathrm{~cm}$ section, and it is considered that there was a significant difference in the $2 \mathrm{~cm}$ section. Further, if an elderly person with poor balance stands on one leg and pushes the walker with the other leg to overcome obstacles, the possibility of a fall accident increases. In the difference of lower extremity muscle activity according to the height of the obstacles, the muscle activity did not significantly increase according to the height difference in the case of CTW. On the other hand, when the GTW was used, muscle activity significantly increased in most muscles. In particular, there was a high increase in the GA and TA muscles. The GA muscle is related to the knee and ankle joints, and the TA muscle is involved in the dorsiflexion of the ankle joint [38]. This result means that the muscle activity of TA and GA increased according to the height of the obstacle because the force of bending the knee and instep was used together in the motion of pushing the GTW. When walking using the CTW, both upper and lower extremity muscle activity decreased. In conclusion, CTW is expected to have a positive effect on preventing falls caused by missing the walker and excessive muscle use on obstacle terrain.

In a previous study, comparing the kinematic factors of the elderly and adults when walking on an incline, the upper body movement of the elderly increased compared to that of the general adult group, which means that the instability of walking and the risk of falls increased [39]. A walker can play a very important role in stabilizing the upper extremities and maintaining balance when elderly people walk on sloped terrain. However, when using a general walker in sloped terrain, the walker is moved by an external force due to kinetic energy in accordance with the slope [40]. Therefore, the elderly use the upper and lower extremity muscles to offset external forces. Due to this process, muscle fatigue will be accumulated. In the uphill section, when using CTW, the activity of the FDP and TB muscles in the upper extremity muscles and all lower extremity muscles significantly decreased compared to when using GTW. In the results from the GTW, the muscle activity of FDP and TB muscles increased. This increasing activity means that these muscles are mainly used for pushing an object, and they were used to offset the external backward force of the walker [41]. In the results of the static stability test, CTW showed stability without movement even at a 20-degree inclination because of the frictional force caused by the wide contact surface of the caterpillar. Based on this static stability, it can be concluded that the muscle activity in the upper and lower extremities was significantly reduced in the absence of the phenomenon of an external force causing the walker to slide down when CTW was used. Moreover, when the inclination angle was increased from 10 degrees to 20 degrees, muscle activity had a tendency to increase when using both CTW and GTW. In particular, the activity of the TB muscle increased significantly when the GTW was used. This means that as the angle increased, a great amount of force was used to push the walker forward, and the activity of the TB muscle increased accordingly. In the downhill section, when using CTW, activity in the FDS and BB muscles significantly decreased in upper extremity muscles compared to when using GTW. In the case of GTW, the muscle activity increased in FDS and BB muscles, which are mainly used when pulling an object. It seems to have been used to offset the external force generated in the backward direction [42]. It is considered that the significant decrease in the activity of the FDS and BB muscles during the period using CTW results from the manifestation of the phenomenon that the walker did not go down due to the caterpillar. It is considered that when using the CTW, a significant decrease in the activity of the FDS and BB muscles did not occur due to the backward phenomenon not occurring in the presence of a caterpillar mounted on the walker. When the downhill inclination angle was increased from 10 degrees to 20 degrees, both muscle activities increased in the conditions using CTW and GTW and significantly increased in the $\mathrm{BB}$ and FDP muscles when the GTW was used. This means that when the angle increases in the downhill section, the usage of all upper and lower extremity muscles increases, and the $\mathrm{BB}$ and FDP muscles are more activated as the walker is pulled toward the body while 
holding it tightly so that it does not roll down. When CTW was used, the activity of most of the upper and lower extremity muscles was significantly reduced compared to using GTW. Therefore, it is possible to prevent collision accidents or falls caused by the loss of a walker by using the CTW.

In the result of walking speed on uneven terrain and obstacle terrain, it can be seen that the walking speed increased when using CTW compared to when using GTW but decreased in sloped terrain. When walking on uneven terrain and obstacle terrain, the GTW's wheel got stuck on gravel or obstacles and could not move forward, so walking was delayed. Therefore, it is considered that the reduced walking speed results from decreased stability of walking when on uneven terrain and obstacle terrain. However, in the sloped terrain, the CTW walking speed decreased compared to the GTW. The previous studies about the walking speed of elderly people using an electric walker and general walker show that the speed of walking with an electric walker is faster than those of walking with a general walker. This is similar to the results of our study [43]. Since the speed of the electric walker is stationary and set to a low speed for safety, it is considered that the speed is lower than that of the general walker on a flat floor. As the angle increased from 10 degrees to 20 degrees in the uphill and downhill sections, the walking speed decreased. In the study of the walking speed of elderly people according to the inclination angle, the walking speed tended to decrease as the inclination angle increased [44]. In addition, looking at the muscle activity corresponding to the inclination angle in this study, it can be seen that the TB muscle in the uphill section of GTW and the BB and FDP muscles in the downhill section significantly increase as the inclination angle increases. This presumably increased the activity of the upper muscles as the speed decreased due to unstable walking when the angle increased, and the user relied on the walker. Based on the above results, it will be possible to continue research on the speed control of the walker suitable for the individual walking speeds of the user in the future.

As a result of the satisfaction evaluation, it was confirmed that when CTW was used, satisfaction was higher in all items compared to GTW, and the reliability between items was higher. Due to the CTW's caterpillar wheels and battery, the weight difference from the GTW was about $30 \mathrm{~kg}$, but there was no difference in satisfaction with the weight of the item, so it is concluded that the weight does not have a significant effect on the inconvenience. Compared to GTW, CTW showed the largest difference in satisfaction in terms of comfort and effectiveness, so it is expected that the use of the developed walker will help elderly people by providing comfortable and efficient walking assistance.

\section{Limitations}

This study has a limitation. The limitation is the composition of the participant group. As the study sample included the elderly with normal walking ability. The elderly who can walk normally may use or need a walker, but it is not essential. This is not the overall target group of such a walker.

\section{Conclusions}

In this study, a caterpillar-type walker was developed to assist elderly people in order to exert muscles less while achieving a stable gait even on uneven terrain, obstacle terrain, and inclined terrain. When using the GTW and CTW, upper and lower extremity muscular activity, the number of overcome obstacles, and walking speed were compared and examined for each terrain, and satisfaction was assessed.

The CTW maintained a stable and static state even on an incline higher than the existing ISO standard. In addition, when using the CTW, the activity of upper and lower extremity muscles was significantly reduced compared to when using the GTW in uneven terrain, obstacle terrain, and inclined terrain. When using GTW, the activity of both upper and lower extremity muscles increased significantly with the increase in obstacles or inclination angles. In contrast, there was no tendency to increase muscle activity when using the CTW. Additionally, the 2-cm-high obstacles could not be overcome when using 
the GTW, but all were overcome when using the CTW. As a result of comparing the walking speed, it was found that the walking speed was faster when using a CTW in uneven terrain and obstacle terrain than when using the GTW. When comparing the satisfaction level, the average overall satisfaction score was higher in the CTW, and satisfaction increased the most in terms of safety, comfort, and effectiveness. From these results, it can be seen that the CTW can be easily used in external environments with uneven terrain, obstacle terrain, and inclined terrain compared to the GTW equipped with circular wheels. Therefore, it can be confirmed that the CTW can assist elderly people with reduced muscle strength in walking conveniently and safely.

In the future, we plan to conduct research on a variable walker that can be used by selecting GTW and CTW according to the ground conditions so that it can be used for rehabilitation of not only the elderly but also patients with walking difficulties.

Author Contributions: Conceptualization, Y.-K.L.; methodology, Y.-K.L., J.-Y.J. and S.K.; formal analysis, Y.-K.L.; investigation, Y.-K.L., J.-Y.J. and C.-M.Y.; writing-original draft preparation, Y.-K.L.; writing-review and editing, Y.-K.L. and J.-J.K.; project administration, J.-J.K.; funding acquisition, J.-J.K. All authors have read and agreed to the published version of the manuscript.

Funding: This work was supported by a National Research Foundation of Korea (NRF) grant funded by the Korea government (MSIT) (No. NRF-2019R1A2C1008454).

Institutional Review Board Statement: The study was conducted according to the guidelines of the Declaration of Helsinki, and approved by the Ethics Committee of Jeonbuk National University Bioethics Review Committee (protocol code 2021-09-008-001 and date of approval 30 September 2021-9 September 2022).

Informed Consent Statement: Informed consent was obtained from all subjects involved in the study.

Data Availability Statement: All relevant data are within the manuscript and available from the corresponding author on request.

Acknowledgments: This paper was proofread by the Writing Center at Jeonbuk National University in November 2021.

Conflicts of Interest: The authors declare no conflict of interest.

\section{References}

1. Park, C.J.; Kim, B.G.; Haan, C.H. Investigation of the listening environment of classrooms for elderly people using speech intelligiblity tests. Acoust. Soc. Korea 2021, 40, 18-30. [CrossRef]

2. Atia, C.M. Human-Smart Rollator Interaction for Gait Analysis and Fall Prevention Using Learning Methods and the i-Walker. Ph.D. Thesis, Polytechnic Universiry of Catalonia, Barcelona, Spain, 2018.

3. Kwon, H.C.; Choi, S.R.; Cho, Y.R.; Lee, H.J.; Tae, K.S. Biomechanical Analysis in the Lower Extremities During Walking with a Four Wheeled Walker (Rollator) Using the Motion Analysis System. J. Rehabil. Welf. Eng. Assist. Technol. 2018, 12, 241-248. [CrossRef]

4. Park, K.-W. Gait Disturbances in Elderly Life. J. Korean Neurol. Assoc. 2017, 35, 10-15. [CrossRef]

5. Lu, T.; Song, Q.-H.; Xu, R.-M.; Guo, Y.-H.; Wang, F.; Hu, J.-P.; Wang, Y.; Zhang, L.-Y. Dance combined with magnetic pulse stimulates the ability of walk and balance in elder people. Int. J. Clin. Exp. Med. 2015, 8, 4381-4386. [PubMed]

6. Park, Y.J.; Bae, I.Y.; Song, S.I. A study on universal walker design for elders with bent back. J. Korean Cryst. Growth Cryst. Technol. 2017, 27, 206-211. [CrossRef]

7. Oh, J.-G.; Cho, W.-J. The effect of lower body muscles strength exercise program on the isokinetic strength and fall prevention fitness of the elderly women. Korean J. Sports Sci. 2018, 27, 1225-1235. [CrossRef]

8. Rubenstein, L.Z. Falls in older people: Epidemiology, risk factors and strategies for prevention. Age Ageing 2006, 35, 37-41. [CrossRef] [PubMed]

9. Zhang, X.; Li, J.; Hu, Z.; Qi, W.; Zhang, L.; Hu, Y.; Su, H.; Ferrigno, G.; De Momi, E. Novel Design and Lateral Stability Tracking Control of a Four-Wheeled Rollator. Appl. Sci. 2019, 9, 2327. [CrossRef]

10. Zhang, X.; Li, J.; Fan, K.; Chen, Z.; Hu, Z.; Yu, Y. Neural Approximation Enhanced Predictive Tracking Control of a Novel Designed Four-Wheeled Rollator. Appl. Sci. 2019, 10, 125. [CrossRef]

11. De Mettelinge, T.R.; Cambier, D. Understanding the Relationship Between Walking Aids and Falls in Older Adults: A pro-spective cohort study. J. Geriatr. Phys. Ther. 2015, 38, 127-132. [CrossRef] [PubMed] 
12. Moon, C.W.; Kim, K.H. A study on the Design Satisfaction and Requirements for User Experience for Walking Frames. Korean Soc. Basic Des. Art. 2016, 17, 127-138.

13. Yeaser, A.; Tung, J.; Huissoon, J.; Hashemi, E. Learning-Aided User Intent Estimation for Smart Rollators. In Proceedings of the 2020 42nd Annual International Conference of the IEEE Engineering in Medicine \& Biology Society (EMBC), Montreal, QC, Canada, 20-24 July 2020; pp. 3178-3183.

14. Roh, H.L.; Shin, E.J. Gait Analysis of Walker Depending External Loads. In Proceedings of the Conference on Korea Academy Industrial Cooperation Society, Jeongseon, Korea, 22-23 May 2015; pp. 631-634.

15. Kim, B.M.; Lee, W.Y.; Lee, E.H. Foldable Electric Walking Design and Production for the Elderly. J. Rehabil. Welf. Eng. Assist. Technol. 2014, 8, 299-303.

16. Koumpouros, Y.; Toulias, T.L.; Tzafestas, C.S.; Moustris, G. Assessment of an intelligent robotic rollator implementing navigation assistance in frail seniors. Technol. Disabil. 2020, 32, 159-177. [CrossRef]

17. Costamagna, E.; Thies, S.B.; Kenney, L.P.J.; Howard, D.; Lindemann, U.; Klenk, J.; Baker, R. Objective measures of rollator user stability and device loading during different walking scenarios. PLoS ONE 2019, 14, e0210960. [CrossRef] [PubMed]

18. Bertrand, K.; Raymond, M.-H.; Miller, W.C.; Ginis, K.A.M.; Demers, L. Walking Aids for Enabling Activity and Participation. Am. J. Phys. Med. Rehabil. 2017, 96, 894-903. [CrossRef] [PubMed]

19. Lee, D.K.; Kong, J.S.; Goh, M.S.; Lee, E.H. Vibration Reduction Algorithm at the Walking-will Recognition on Uneven Terrain. J. Korean Inst. Intell. Syst. 2011, 21, 42-48. [CrossRef]

20. Zhang, X.; Mu, X.; Xu, H.; Alhassan, A.B.; Kadry, H.K. Vibration Characteristics Analysis of Human- Robot Coupled System for Walking Posture of Elderly-Assistant Robot. IEEE Access 2021, 9, 44217-44235. [CrossRef]

21. Choi, H.S.; Kim, M.K.; Shin, G.W.; Kim, J.K.; Kim, I.Y.; Baek, Y.S. Development of the Algorithm for Controlling the Electric Walking Aids on the Slope by Using FSR Foot Sensor. In Proceedings of the Conference on JKSPE, Gwangju, Korea, 13-15 December 2017; pp. 611-612.

22. Lee, K.S.; Kim, K.R.; Kim, H.C.; Chae, H.S.; Kim, S.W.; Seo, M.T. Development and Evaluation of Rollator for Elderly Farmers J. Ergon. Soc. Korea 2014, 33, 487-497. [CrossRef]

23. Kim, Y.G.; Kim, J.W.; Kwak, J.H.; Hong, D.H.; Lee, K.D.; An, J.U. Wheel \& Track Hybrid Mobile Robot Platform and Mechanism for Optimal Navigation in Urban Terrain. J. Korea Robot. Soc. 2010, 5, 270-277.

24. Kong, J.-Y. Satisfaction Evaluation for Orthoses by using QUEST. J. Korea Acad. Coop. Soc. 2016, 17, 109-116. [CrossRef]

25. Kim, K.S.; Kim, Y.R. Biomechanical Model of Hand to Predict Muscle Force and Joint Force. J. Ergon. Soc. Korea 2009, $28,1-6$.

26. Lee, J.-S.; Ahn, J.-Y.; Yoon, S.-J. The Effects of Low-Intensity Strength Training after Heat Stress on Lower Extremity Musculoskeletal System and Growth Related Factors in Older Women. Korean J. Sports Sci. 2017, 26, 989-1000. [CrossRef]

27. Jung, J.Y.; Kim, C.S. The Effect of Bilateral Tapping Training on the Intensity of Triceps Muscle Activities and Reaching Time of Affected Upper Limb in Children with Hemiplegia. J. Korean Phys. Ther. 2003, 15, 417-432.

28. Yang, Y.-A. The Responding Strategies of Musculorskeletal Disease in Aging Society. J. Ergon. Soc. Korea 2010, $29,505-511$. [CrossRef]

29. Kim, B.K.; Kim, T.H. The Change of Lower-limb Muscle Activity according to Gait speed when Normal and Assistive Gait of older. Korean Acad. Ortho. Man. Phys. Ther. 2008, 14, 60-67.

30. Shin, S.H.; Kim, M.J.; Ko, H.; Kang, S.-R.; Jeong, H.C.; Hong, C.U.; Kwon, T.K. Analysis of Brain and Muscle Activity in Maintaining Postural Balance According to the Ground Conditions. Trans. Korean Soc. Mech. Eng. B 2020, 44, 169-175. [CrossRef]

31. Lee, W.Y.; Lee, D.K.; Lee, E.H. A Study on The Straightness Improvement Method for Ensure Safety of Mobile Walker in Slope. J. Rehabil. Welf. Eng. Assist. Technol. 2014, 8, 187-196.

32. Kim, S.Y.; Kim, S.M.; Bang, S.Y. Foot Pain and Disability in Community Dwelling Elders. J. Korean Gerontol. Nurs. 2011, 13, 69-78.

33. Park, J.H.; Kim, W.J.; Shin, Y.H.; Kim, J. Development of Backpack Loading Estimation Model using Surface Electromyography (SEMG) of Gastrocnemius During Walking and Running. In Proceedings of the Conference on JKSPE, Jeju, Korea, 17-19 May 2017; pp. 711-712.

34. Hwang, M.-J.; Bang, Y.-S.; Son, B.-Y. A Study of the Convenience of Elderly Facilities, Satisfaction of Convenient Facilities, Falls Efficacy and Activities of Daily Living of Senior Users of Walking Aid Living in Permanent Rental Apartments. J. Korea Entertain. Ind. Assoc. 2018, 12, 267-277. [CrossRef]

35. Chung, J.H.; Lee, K.W.; Kim, Y.H. Development of a Pressure Distribution Measurement System. J. Biomed. Eng. Res. 2000, 21, 213-218.

36. Jeong, S. Improving Sidewalk Design Standard in Seoul: Learning from the Foreign Standards. Seoul Stud. 2007, 8, 139-153.

37. Kim, E.S.; Park, K.N. Development of Walking and Rehabilitation Assistance Device for Knee Joint. J. Rehabil. Welf. Eng. Assist. Technol. 2021, 15, 158-163. [CrossRef]

38. Kang, Y.S.; Hong, C.U.; Han, J.K.; Yu, M.; Kwon, T.K. Safety Evaluation of Elevator-type Evacuation by Bio-Signal Analysis in Repeated Evacuation Training. J. Rehabil. Welf. Eng. Assist. Technol. 2021, 15, 164-171. [CrossRef]

39. Choi, J.-S.; Kang, D.-W.; Mun, K.-R.; Bang, Y.-H.; Tack, G.-R. Comparison of Kinematic Factors between Old and Young People during Walking on Level and Uneven Inclined Surfaces. Korean J. Sport Biomech. 2010, 20, 33-39. [CrossRef]

40. Lee, W.Y.; Lee, D.K.; Goh, M.S.; Lee, E.H. The study of overcome the ramps for mobile walker. In Proceedings of the Conference on Journal of RWEAT, Goyang, Korea, 10-12 November 2011; pp. 167-170. 
41. Jang, H.M.; Sohn, J.W. Design of Prosthetic Robot Hand and Electromyography-Based Hand Motion Recognition. J. Korean Soc. Precis. Eng. 2020, 37, 339-345. [CrossRef]

42. Kang, K.-H.; Hwan, K. The Study about Muscle Activities and ROM of Shoulder Joint according to Supination during External Rotation. J. Korean Soc. Wellness 2017, 12, 553-563. [CrossRef]

43. Choi, H.-J.; Kang, S.-J.; Kwon, C.-Y.; Ryu, J.-C.; Lee, S.-M.; Mun, M.-S. Research of Elderly Gait-assistant-robot Control System. J. Inst. Control. Robot. Syst. 2010, 16, 823-826. [CrossRef]

44. Cho, W.; Park, M.I.; Noh, C.G.; Park, B.J.; Kim, H.S. Gait Analysis of Stability according to the Inclination of the Ramps in elderly Adults. In Proceedings of the Conference on JKSPE, Jeju, Korea, 11-13 May 2016; pp. 879-880. 